\title{
Effects of litter size and subsequent gold-thioglucose-induced obesity on adipose tissue weight, distribution and cellularity in male and female mice: an age study
}

\author{
BY JENNIFER L. ROBERTS, FRANCES M. WHITTINGTON AND \\ MICHAEL ENSER
}

AFRC Institute of Food Research, Bristol Laboratory, Langford, Bristol BSI8 7DY

(Received 14 September 1987 - Accepted 21 January 1988)

\begin{abstract}
1. Over- or undernutrition of newborn mice was caused by suckling in litters consisting initially of four or eighteen pups. After weaning mice were fed $a d$ lib. At 13 weeks of age some mice from large litters received gold thioglucose (GTG: $600 \mathrm{mg} / \mathrm{kg}$ intraperitoneally) to induce hyperphagia, and mice were killed at 13, 19.5, 26, 39 and 52 weeks.
\end{abstract}

2. Total carcass lipid and the size and number of adipocytes in the inguinal subcutaneous, genital, perirenal and mesenteric depots were determined.

3. Mice, both male and female, raised in small litters were heavier and had more carcass fat at all ages than mice raised in large litters. After GTG-treatment mice from large litters were heavier and fatter than mice raised in small litters.

4. Fat distribution between the depots was related to carcass lipid content and not to treatment. The order of depot development was subcutaneous, parametrial, perirenal and mesenteric in females and epididymal, subcutaneous, perirenal and mesenteric in males. At 13 weeks the depots in males were more developed than those in females.

5. Litter size had no effect on adipocyte volume in female mice at 13 weeks but by 52 weeks small-litter mice had larger cells in all depots and more cells in the parametrial and perirenal depots.

6. Male mice from small litters had bigger cells at 13 weeks in all depots compared with males from large litters but by 52 weeks no significant differences remained. Greater numbers of cells were present only in the perirenal and mesenteric depots of small-litter males at some ages.

7. Depots of GTG-treated large-litter female mice had larger cells than those of small-litter females, while a similar number of cells was found by $\$ 2$ weeks in all but the perirenal depot, which had significantly more cells.

8. GTG treatment of male mice from large litters also caused bigger cells than in small-litter mice, and an increased depot cell number at earlier ages in all but the epididymal depot. By 52 weeks cell numbers were similar in depots from small-litter and GTG-treated large-litter mice, except for the epididymal depot from the latter which had fewer cells.

9. Increases in cell numbers with age in different depots occurred independently of existing cell mean volume and even of tissue growth, suggesting the presence of an in-built chronology, at least in older mice.

10. We suppose that the differences in response to the level of preweaning nutrition in males and females result from a greater effect on the hypothalamic appetite centre in the latter. Whereas the cellular changes in large-litter males occur in the late-developing depots and are reversed naturally with time, those in the large-litter females are more extensive and require induction of hyperphagia for reversal.

Undernourishment of rats and mice during the suckling period may cause a reduction in the number and size of adipocytes (Knittle \& Hirsch, 1968; Aubert et al. 1971; Martin, 1974; Eisen \& Leatherwood, 1978). Conversely, overnutrition during later stages of growth, induced by feeding high-fat diets (Lemonnier, 1972; Faust et al. 1978) or by hypothalamic damage (Johnson \& Hirsch, 1972; Wise, 1975) results in obesity with an increase in the number and size of fat cells. Most of the effects of preweaning undernutrition on the cellularity of adipose tissue can be reversed by feeding high-fat diets (Faust et al. 1980; Hausberger \& Volz, 1984). Such reversal is not specific to high-fat diets since we observed that reversal could also occur in mice fed on a normal commercial pelleted diet if they were made hyperphagic (Enser et al. 1985).

In that previous study, mice were raised in large litters of eighteen (LL) or small litters of four (SL), and after weaning were allowed to feed ad lib. The response of adipocyte 
number and volume to this regimen depended on the depot and the sex of the mice. Female SL mice had more and larger adipocytes in their subcutaneous inguinal, gonadal, perirenal and mesenteric depots than female LL mice. In male mice, however, fat-cell number appeared unchanged by preweaning undernutrition in the four depots studied, differences in cell volume explaining the differences in depot size. Since the mice were killed and analysed at 39 weeks of age it was not clear whether adipocyte number had been depressed by the shortage of milk and had 'caught up' subsequently. Male mice also differed from female mice in their response to gold thioglucose (GTG)-induced hyperphagia from 13 weeks of age. GTG treatment reversed the effects of litter size in female LL mice, restoring the size and number of adipocytes in their depots to similar or even higher levels than those in untreated SL mice. Cell numbers in male depots, whether from LL or SL mice, were not increased by GTG treatment despite a marked increase in lipid deposition. Because the rapid growth occurred soon after treatment, it is again possible that early differences in cellularity might have been lost by 39 weeks. We have, therefore, extended our previous investigation into a longitudinal study to discover if and when increases in apparent cell number occurred.

The stimulus for the development of 'new' recognizable adipocytes is not clear. Faust et al. (1978) proposed that hyperplasia occurs when existing cells reach a critical size. This view has been supported in studies of humans (Björntorp et al. 1982) and cattle (Robelin, 1981). However, Stiles et al. (1975) observed an increase in adipocyte number in the epididymal adipose tissue of adult rats when depot weight remained constant and hence mean cell volume decreased. Hausman (1985) has questioned the evidence for the "critical size' hypothesis, and Reyne et al. (1985) have suggested that different mechanisms may operate to regulate cell number in growing and mature animals. To gain further insight into this problem we have investigated the distribution of cell size in adipose tissues of mice in the present longitudinal study in order to relate changes in cell number to differences in the size of the existing population.

\section{EXPERIMENT AL}

Litters of eighteen (LL) and four (SL) mice of the strain CFLP were raised in our own colony by the method described previously (Enser et al. 1985). They were weaned at $21 \mathrm{~d}$ of age onto Oxoid breeding diet (Styles, Bewley) containing $176 \mathrm{~g}$ protein $/ \mathrm{kg}$ and $11.9 \mathrm{MJ}$ metabolizable energy $/ \mathrm{kg}$. Treatment of LL mice with GTG (Sigma Chemical Co. Ltd, Poole, Dorset) was by intraperitoneal injection of $600 \mathrm{mg} / \mathrm{kg}$ at 13 weeks of age. Mice that did not respond with rapid weight gain were discarded. Mice were killed at 13, 19.5, 26, 39 and 52 weeks of age after $24 \mathrm{~h}$ starvation.

Four adipose depots, the inguinal subcutaneous, gonadal, perirenal including retroperitoneal, and mesenteric, were dissected out and weighed. The diameters of 100 cells from each depot were measured by the microscopic method of Sjöström et al, (1971). The 100 cells comprised approximately thirty-three from each of three widely spaced samples whose diameters did not differ significantly. A graticule with $6 \mu \mathrm{m}$ divisions was used: all cells which the centre line intersected were measured, to avoid bias. The lipid in the four depots and in the residual carcass minus the material in the gut was extracted with diethyl ether as described previously (Enser et al. 1985). The volume of lipid in each depot was calculated by assuming a density of $0.91 \mathrm{~g} / \mathrm{ml}$, and this was divided by the sum of the volumes of the measured cells to give adipocyte number per depot. The frequency distribution of each sample of 100 cells was smoothed by finding the mean of the frequencies for each trio of 'adjacent' cell sizes. Then the total number of cells at each size was calculated for the depot of each animal, and finally the mean cell number at each size was calculated for each group of animals. 
Table 1. Carcass weight and lipid content of mice from small litters $(S L)$, large litters $(L L)$ and large litters treated with gold thioglucose (GTG) (LL GTG) at different ages (Mean values with their standard errors; the values of $n$ are the no. of animals)

\begin{tabular}{|c|c|c|c|c|c|c|c|c|c|}
\hline \multirow{2}{*}{$\begin{array}{c}\text { Age } \\
\text { (weeks) }\end{array}$} & \multicolumn{3}{|c|}{ LL } & \multicolumn{3}{|c|}{ SL } & \multicolumn{3}{|c|}{ LL GTG } \\
\hline & Mean & $\mathrm{SE}$ & $n$ & Mean & $\mathrm{SE}$ & $n$ & Mean & $\mathrm{SE}$ & $n$ \\
\hline \multicolumn{10}{|l|}{ Female mice } \\
\hline \multicolumn{10}{|c|}{ Carcass wt (g) } \\
\hline 13 & $21 \cdot 1^{\mathrm{a}}$ & 0.8 & 8 & $24 \cdot 4^{a}$ & 0.8 & 8 & $21 \cdot 1^{\mathrm{a}}$ & 0.8 & 10 \\
\hline $19 \cdot 5$ & $25 \cdot 6^{\mathrm{a}}$ & 0.8 & 8 & $30 \cdot 2^{\mathrm{a}}$ & 1.9 & 3 & $44 \cdot 8^{\mathrm{b}}$ & 1.7 & 9 \\
\hline 26 & $28 \cdot 4^{b}$ & 2.0 & 3 & $44 \cdot 1^{\mathrm{D}}$ & 3.3 & 3 & $65 \cdot 4^{\mathrm{e}}$ & 3.3 & 4 \\
\hline 39 & $34 \cdot 8^{\mathrm{c}}$ & 1.5 & 16 & $47.5^{b}$ & 1.9 & 15 & $67 \cdot 2^{\mathrm{c}}$ & 1.6 & 18 \\
\hline 52 & $34 \cdot 2^{\mathrm{c}}$ & 0.9 & 20 & $49 \cdot 8^{b}$ & $1 \cdot 9$ & 14 & $67 \cdot 6^{\mathrm{c}}$ & 1.8 & 18 \\
\hline \multicolumn{10}{|c|}{ Carcass lipid (g) } \\
\hline 13 & $1 \cdot 1^{\mathrm{a}}$ & $0 \cdot 3$ & & $1 \cdot 8^{\mathrm{a}}$ & 0.4 & & $1 \cdot 1^{\mathrm{a}}$ & 0.3 & \\
\hline $19 \cdot 5$ & $2 \cdot 5^{\mathrm{a}}$ & 0.4 & & $5 \cdot 2^{a}$ & 1.0 & & $19 \cdot 1^{\mathrm{D}}$ & 1.2 & \\
\hline 26 & $3 \cdot 2^{\mathrm{a}}$ & 1.2 & & $13 \cdot 1^{\mathrm{b}}$ & 1.6 & & $32 \cdot 8^{\mathrm{c}}$ & 2.6 & \\
\hline 39 & $8 \cdot 6^{\mathrm{h}}$ & 1.3 & & $18 \cdot 3^{\mathrm{c}}$ & 1.7 & & $34 \cdot 5^{\mathrm{c}}$ & 1.3 & \\
\hline 52 & $7 \cdot 6^{\mathrm{b}}$ & 0.7 & & $19 \cdot 0^{c}$ & 1.5 & & $35 \cdot 9^{\mathrm{c}}$ & $1 \cdot 3$ & \\
\hline \multicolumn{10}{|l|}{ Male mice } \\
\hline \multicolumn{10}{|c|}{ Carcass wt $(\mathrm{g})$} \\
\hline 13 & $26 \cdot 1^{\mathrm{a}}$ & 0.7 & 12 & $34 \cdot 3^{\mathrm{a}}$ & $1 \cdot 2$ & 10 & $26 \cdot 1^{\mathrm{a}}$ & 0.7 & 12 \\
\hline 19.5 & $31.9^{\mathrm{b}}$ & $1 \cdot 1$ & 6 & $44 \cdot 6^{\mathrm{b}}$ & 3.9 & 4 & $47.7^{\mathrm{b}}$ & $2 \cdot 4$ & 6 \\
\hline 26 & $40 \cdot 0^{\mathrm{c}}$ & $2 \cdot 1$ & 6 & $51 \cdot 9^{\mathrm{c}}$ & 0.4 & 2 & $62 \cdot 3^{\mathrm{e}}$ & $3 \cdot 3$ & 4 \\
\hline 39 & $45 \cdot 6^{d}$ & 1.6 & 14 & $60 \cdot 4^{d}$ & 1.8 & 12 & $65 \cdot 6^{\mathrm{cd}}$ & 1.4 & 13 \\
\hline 52 & $50 \cdot 0^{\mathrm{e}}$ & $1 \cdot 3$ & 16 & $59 \cdot 5^{\mathrm{d}}$ & 1.5 & 11. & $66 \cdot 6^{\mathrm{d}}$ & $1 \cdot 3$ & 15 \\
\hline \multicolumn{10}{|c|}{ Carcass lipid (g) } \\
\hline 13 & $2 \cdot 3^{\mathrm{a}}$ & 0.3 & & $5 \cdot 3^{a}$ & 0.7 & & $2 \cdot 3^{\mathrm{a}}$ & 0.3 & \\
\hline $19 \cdot 5$ & $4 \cdot 1^{\mathrm{a}}$ & 0.5 & & $12 \cdot 9^{\mathrm{b}}$ & $2 \cdot 9$ & & $18 \cdot 0^{\mathrm{b}}$ & 2.0 & \\
\hline 26 & $9.1^{10}$ & 1.6 & & $16 \cdot 2^{\mathrm{C}}$ & 0.1 & & $26 \cdot 6^{\mathrm{c}}$ & 27 & \\
\hline 39 & $14.7^{\circ}$ & $1 \cdot 3$ & & $23 \cdot 7^{\mathrm{a}}$ & 1.3 & & $29 \cdot 6^{\mathrm{c}}$ & 1.5 & \\
\hline 52 & $17.7^{\circ}$ & 0.9 & & $21 \cdot 3^{d}$ & 0.9 & & $28 \cdot 5^{c}$ & 1.0 & \\
\hline
\end{tabular}

a-e Within vertical columns, treatment means followed by different superscript letters differed significantly $(P<0.05)$.

Results are expressed as means with standard errors and compared by analysis of variance. The significance of age effects is shown in the tables. Where the term 'significant' is used in the text referring to treatment or other comparisons it refers to differences with $P<0.05$. Simple linear regression was used to obtain correlation coefficients and regression constants.

\section{RESULTS}

Carcass weight and lipid content

The growth of the mice resembled the pattern we have reported previously (Enser $e t$ al. 1985). Weight gain had ceased by 39 weeks of age except in male LL mice (Table 1). Mice raised in small litters were significantly heavier than LL mice at all ages except for females aged 19.5 weeks. Treatment with GTG caused rapid weight gain and carcass weights, measured 7 weeks later, were increased significantly above those of untreated mice and remained higher at subsequent ages. Male mice were heavier than females at a given age or treatment except after GTG treatment when their weights were similar.

Significant deposition of lipid occurred until 39 weeks of age in LL and SL mice and until 26 weeks in GTG-treated mice. In females, SL mice had more lipid than LL mice from 26 


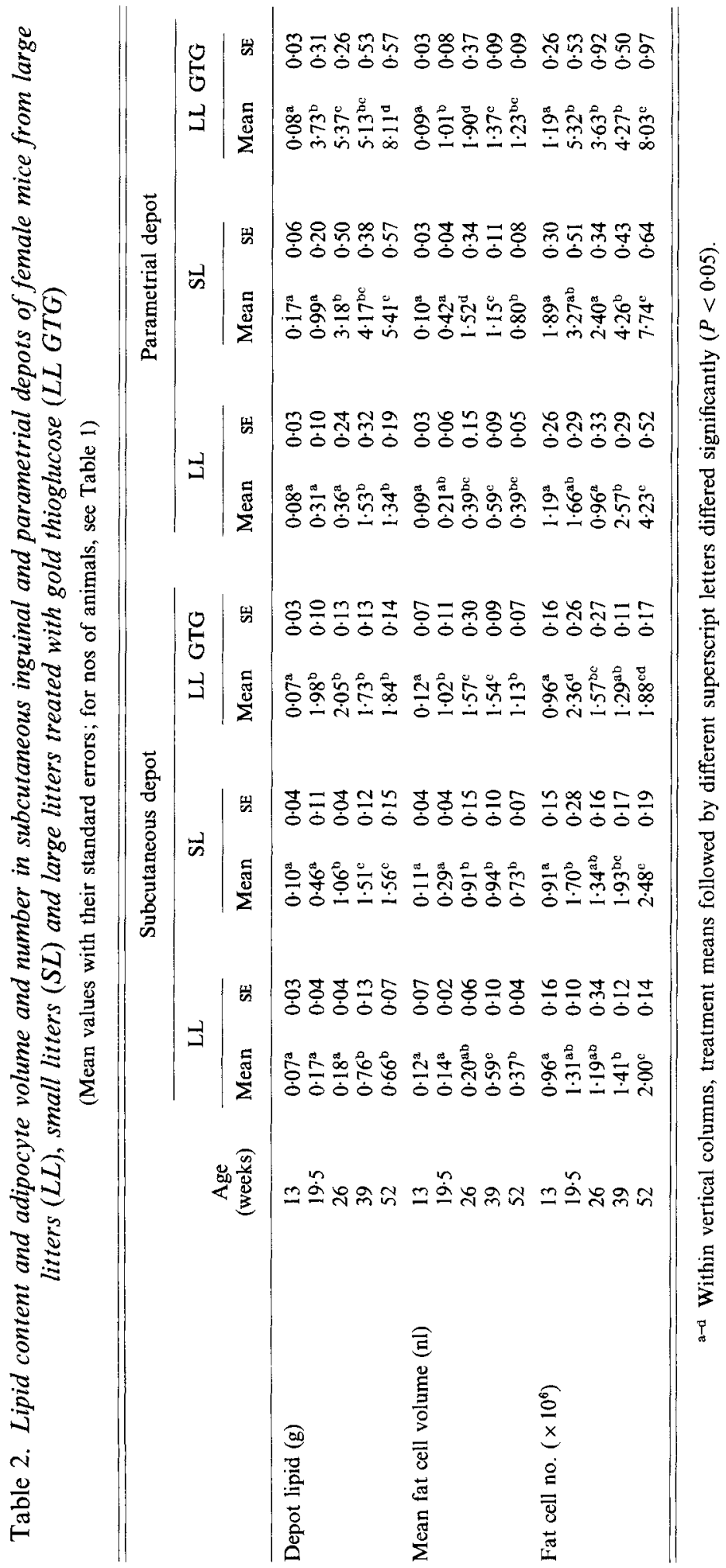




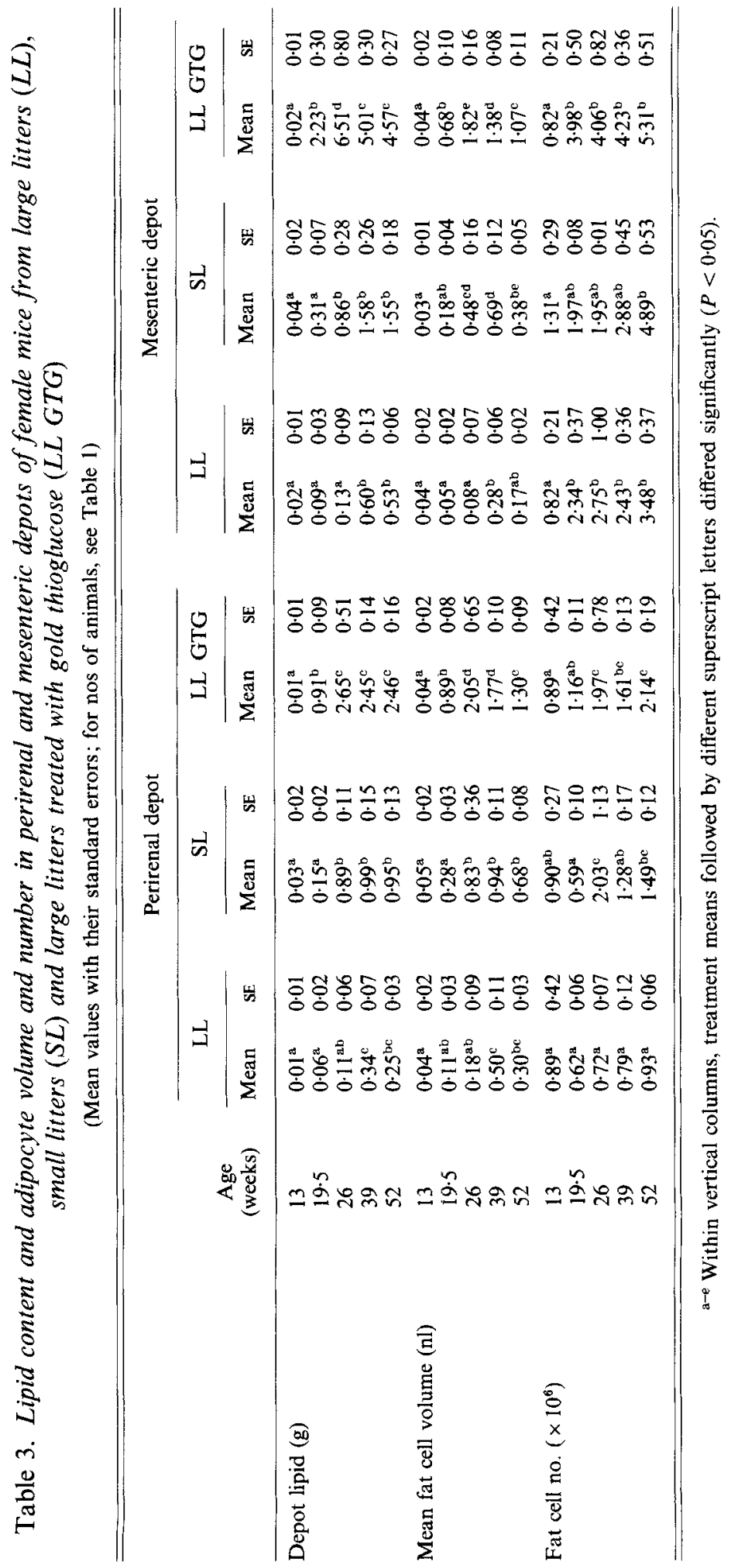




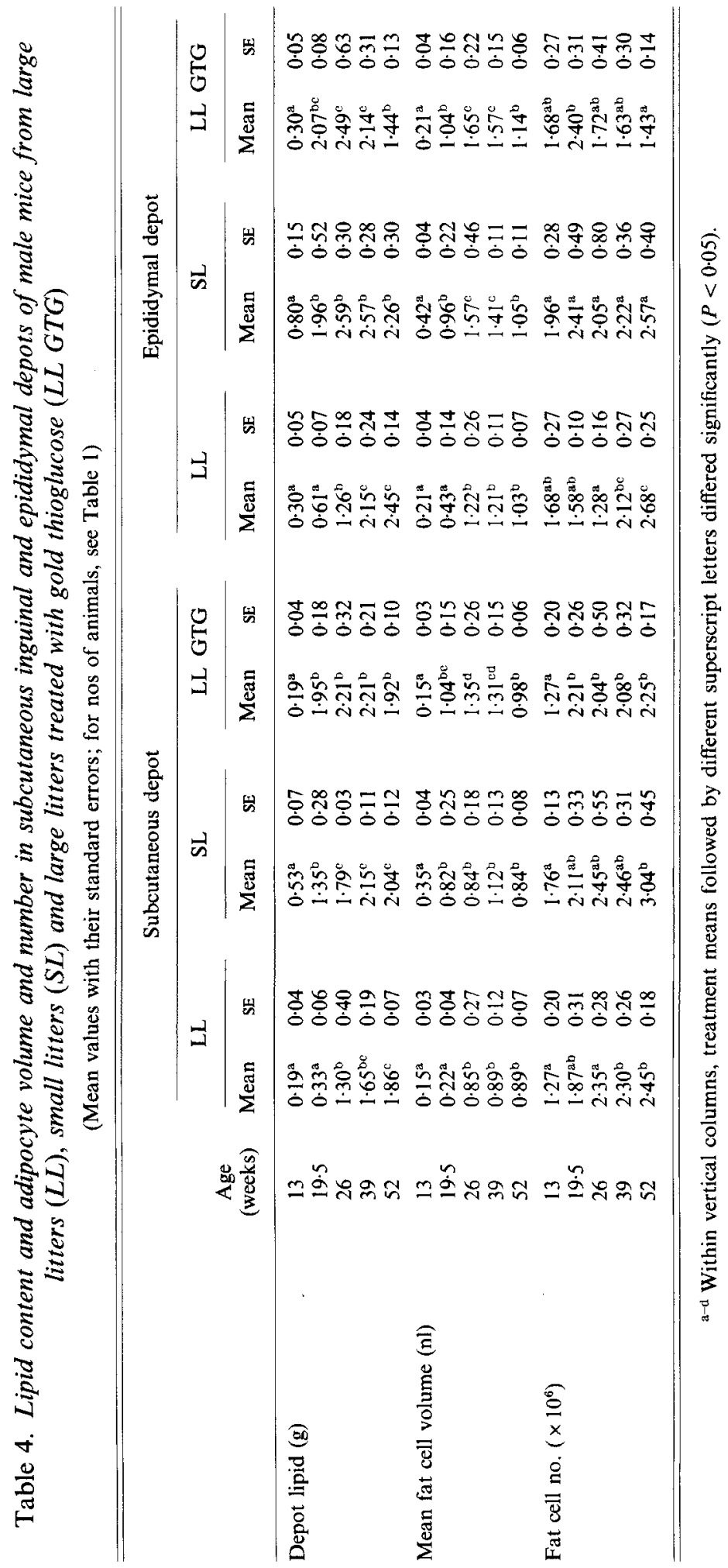




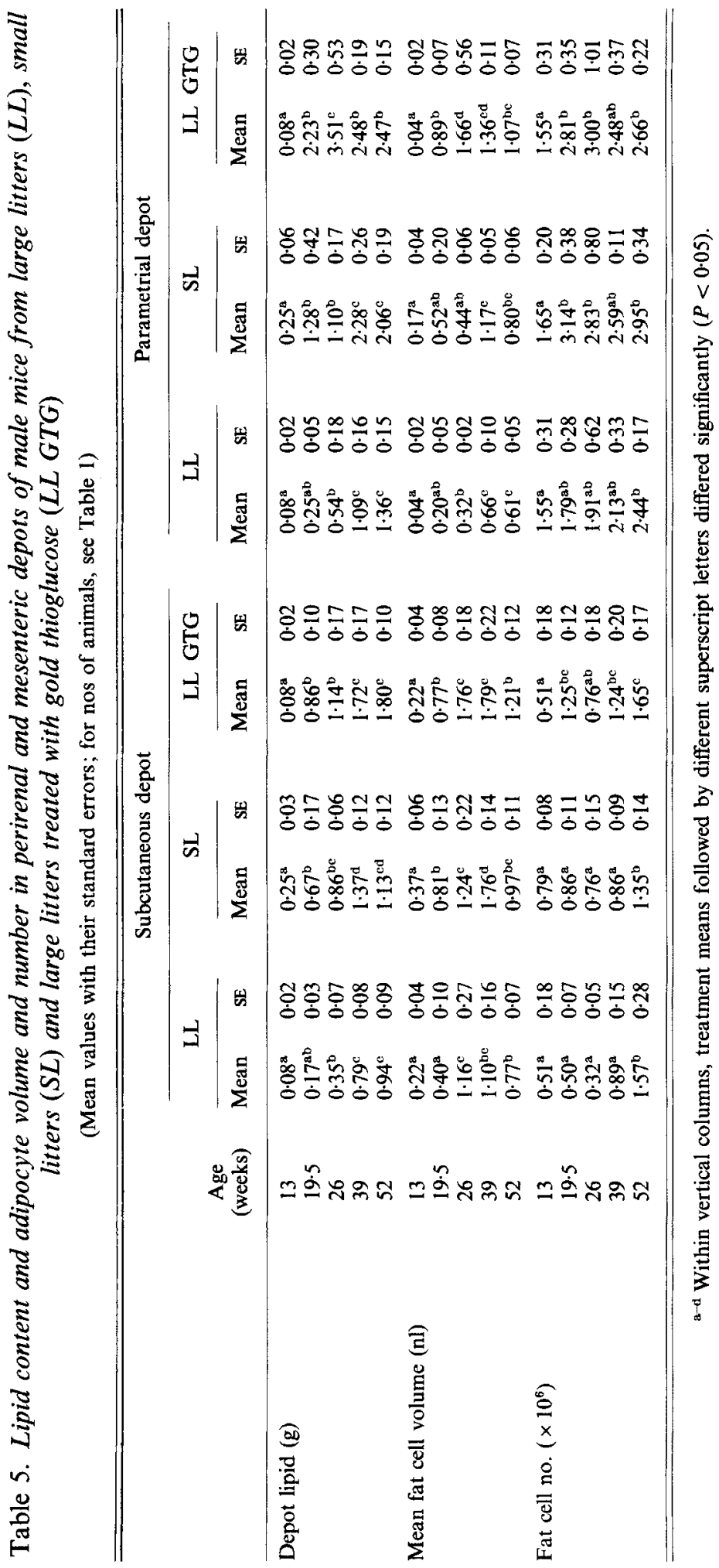


weeks of age $(P<0.05)$, and a greater proportion from 19 weeks. In males, carcass lipid was significantly higher in SL than in LL mice throughout, but the proportion of lipid in the carcass was similar by 52 weeks. Carcass lipid was significantly higher in LL mice after GTG treatment than it was in untreated LL mice. SL females had less carcass lipid than SL males, although by 26 weeks the proportion was similar for the two sexes. For LL mice, female carcasses had a lower mass and proportion of lipid than males. However, GTG treatment reversed this pattern: at 19.5 weeks lipid mass was similar for the two sexes but proportionately more in females; by 26 weeks both quantity and proportion of lipid were greater in females.

\section{Depot weights and adipose tissue distribution in the carcass}

The quantities of lipid present in the four depots studied are shown in Tables 2 and 3 for female mice and Tables 4 and 5 for male mice. The size of the depots generally increased with age as expected, the pattern reflecting that for total body lipid in most cases. Thus for LL mice at a given age, depots were smaller in females than in males, and this held for SL mice except that the parametrial depot was heavier than the epididymal fat pad after 26 weeks. After GTG treatment, female fat depots were larger or of similar size compared with those of treated male mice. Depots usually maintained their weight after a significant period of growth, even after the rapid growth induced by GTG treatment, except for the epididymal fat pad and mesenteric depots. The four female depots were similar in size at 13 weeks but significantly different at 52 weeks in the order LL $<$ SL $<$ LL GTG, except for the inguinal depots from SL and GTG-treated LL mice which were not different $(P>$ $0.05)$. The depots of LL males were significantly smaller than those of SL males at 13 weeks but by 52 weeks this was only true for the mesenteric depot. The size of the depots in GTGtreated LL males reached, but did not exceed consistently, the size of the depots in SL mice, while the size of the epididymal depot decreased significantly between 39 and 52 weeks, becoming smaller than in either SL or LL mice $(P<0.05)$, The mesenteric depots in both sexes were also significantly heavier at 26 weeks than at 52 weeks, in GTG-treated mice. The large weight of this depot at 26 weeks in these mice does not seem to stem from the presence of atypically fat mice in the small groups of animals. When the depot weights are expressed as proportions of total body lipid they are appropriate, fitting the age-related pattern. The same argument applies to the epididymal fat pad in GTG-treated males suggesting that the 26-week depot weights are genuine.

In female mice at 13 weeks litter size had no significant effect on the proportion of total body lipid in the depots studied (compare Tables 2 and 3 with Table 1). Their contribution to total body lipid generally increased with age and then reached a plateau, the depots of SL females gaining significantly more by 19.5 weeks and retaining it although eventually the inguinal depot of LL mice reached a similar proportion. The parametrial depot of SL females contributed one-quarter of the total body lipid by 26 weeks. In depots from GTGtreated LL female mice this pattern changed. These depots contained their greatest proportion of body fat at 19.5 or 26 weeks and it declined subsequently. In the early developing inguinal depot the proportion fell to below that in the LL or SL mice by 39 weeks $(P<0.05)$; in the parametrial depot it fell to the LL level by 39 weeks then rose again but did not reach the SL level. In the perirenal and mesenteric depots of GTGtreated females the fall did not prevent the proportion being significantly higher than that in SL or LL mice after 39 weeks.

A litter-size effect on lipid distribution in male mice was present at 13 weeks with the subcutaneous, perirenal and mesenteric depots contributing more to the total body lipid in SL compared with LL mice $(P<0.05)$ (compare Tables 4 and 5 with Table 1$)$. However, at 39 weeks, the difference was present only in the mesenteric depot and had disappeared 
in that depot by 52 weeks. In LL males, the proportion of carcass lipid in the epididymal and mesenteric depots increased significantly by 19 weeks, in the inguinal depot between 26 and 39 weeks, and at both times in the perirenal depot. In SL males, only the mesenteric depot increased its proportion of body fat with age $(P<0.05)$. The perirenal depot held a constant proportion but in the other two depots the proportions fell significantly, ending up below those in the LL mice. GTG treatment resulted in immediate increases in the proportion of lipid in all depots except for the epididymal depot $(P<0.05)$, but there were later significant decreases in all but the perirenal depot. Thus the inguinal and epididymal depots contributed a lower proportion of total lipid at 39 and 52 weeks than in untreated mice $(P<0.05)$, while the perirenal and mesenteric depots were not significantly different.

The four depots of female mice contributed less to the total body lipid than those of males when body-weight was low, particularly at 13 weeks of age or in mice from large litters. This also held for the early developing inguinal depot at all ages and treatments. However, the pattern was reversed in the genital depots of LL mice by 39 weeks and of SL and GTG-treated LL mice by 19 weeks. By 26 weeks, the perirenal and mesenteric depots in GTG-treated LL females also contributed more lipid to the body total than in males.

\section{Adipocyte volume and number}

In 13-week-old females, litter size did not affect mean cell volume or number in the four depots studied (Tables 2 and 3). By 39 weeks depots of SL females had significantly larger cells and, in the parametrial and perirenal depots, significantly higher numbers than in LL females. A transiently higher cell number also occurred at 39 weeks for the SL inguinal depot $(P<0 \cdot 05)$. In LL females, cell volume increased between 26 and 39 weeks, except in the parametrial depot where it occurred between 13 and 39 weeks. Significant cell number increases were seen by 19.5 weeks, except in the perirenal depot, and again after 26 weeks in the parametrial depot or after 39 weeks in the other depots, although not significant in the perirenal depot. These late increases coincided with decreases in mean cell volumes. In SL female mice, cell volume increases were earlier, between 19.5 amd 26 weeks, but the timing of cell number increases was similar to that for LL females although the perirenal depot appeared to show a first increase between 19.5 and 26 weeks. The effect of GTG on the growth of the female depots brought forward and amplified the cell-size increases: volumes rose sharply between 13 and 26 weeks creating significant differences from untreated mice. Again, a significant increase in cell number occurred by 19.5 or 26 weeks in all depots and after 39 weeks except in the mesenteric depot. Cell volumes in GTGtreated LL females were significantly higher than in SL or LL mice after 39 weeks despite the decreases in cell volume which occurred then. However, only in the parametrial depot of GTG-treated mice was cell number consistently higher after 13 weeks than in LL mice $(P<0 \cdot 05)$, although it was significantly higher in the perirenal and mesenteric depots after 39 weeks.

Unlike females, SL males had significantly larger fat cells than LL males in the depots studied at 13 weeks of age, but by 52 weeks, these differences had been eliminated (Tables 4 and 5). In LL males, cells enlarged usually between 19.5 and 26 weeks and thus caught up with SL males where this had occurred earlier. Except in the inguinal depot, cell size increased further in SL males but then tended to fall, causing significant differences from LL males only at 39 weeks in the perirenal and mesenteric depots. Litter size did not affect cell number at 13 weeks, if at all. Except in the epididymal depot the trend was for cell number to increase gradually, regardless of treatment, reaching significance over long periods. As in females, GTG treatment of LL males caused large increases in cell volume to occur up to 26 weeks of age. Thus significant differences from untreated LL mice occurred at 19 weeks, although only in the mesenteric depot at 26 weeks. After this age, 


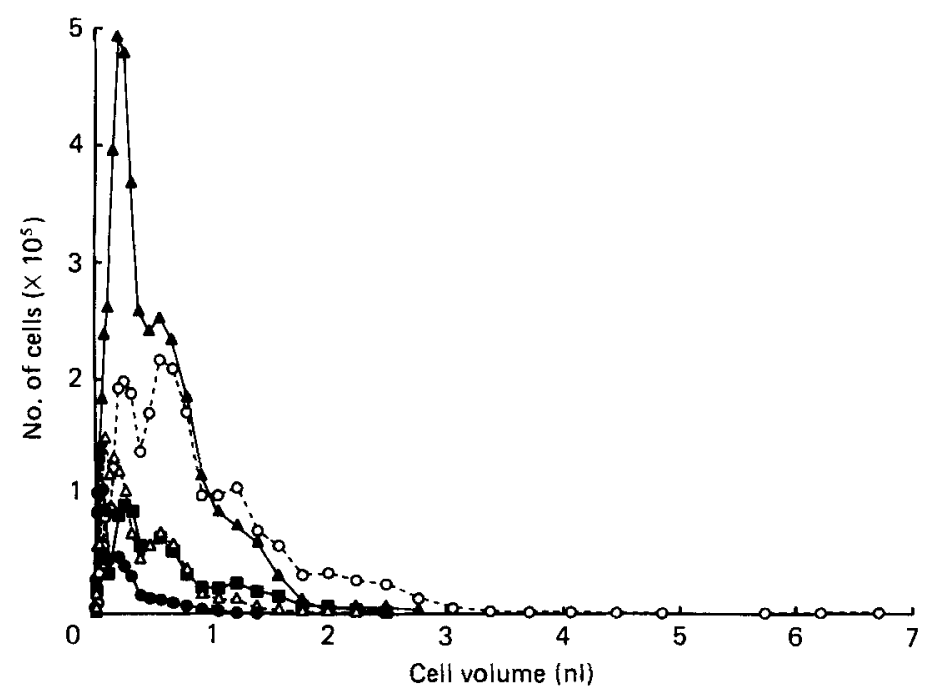

Fig. 1. Adipocyte distributions for the parametrial depot of female mice suckled in large litters of eighteen, aged 13 weeks $(\bullet), 19.5$ weeks $(\triangle), 26$ weeks $(\boldsymbol{D}), 39$ weeks $(O)$ and 52 weeks $(\boldsymbol{\Delta})$. For nos of mice, see Table 1.

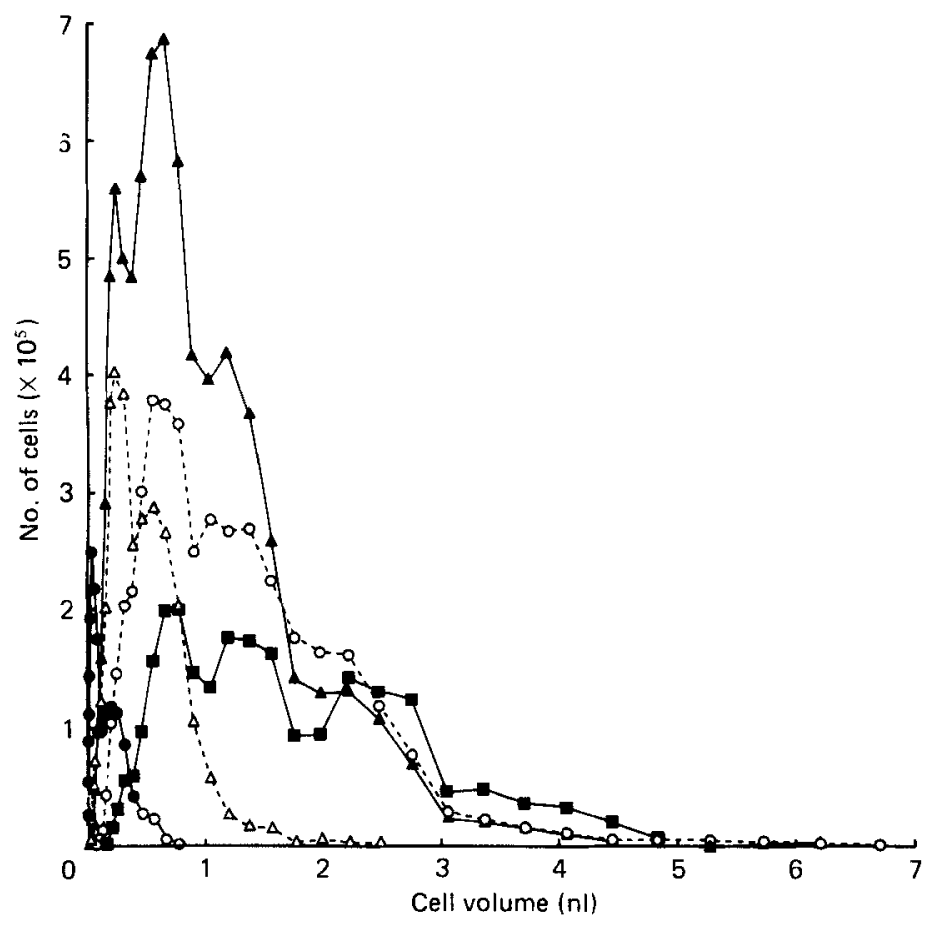

Fig. 2. Adipocyte distributions for the parametrial depot of female mice suckled in small litters of four, aged 13 weeks $(O), 19.5$ weeks $(\triangle), 26$ weeks $(\square), 39$ weeks $(O)$ and 52 weeks $(\Delta)$. For nos of mice, see Table 1. The 39-week distribution extended to cell volumes of $11.75 \mathrm{nl}$ with a total of $5.77 \times 10^{3}$ cells. 


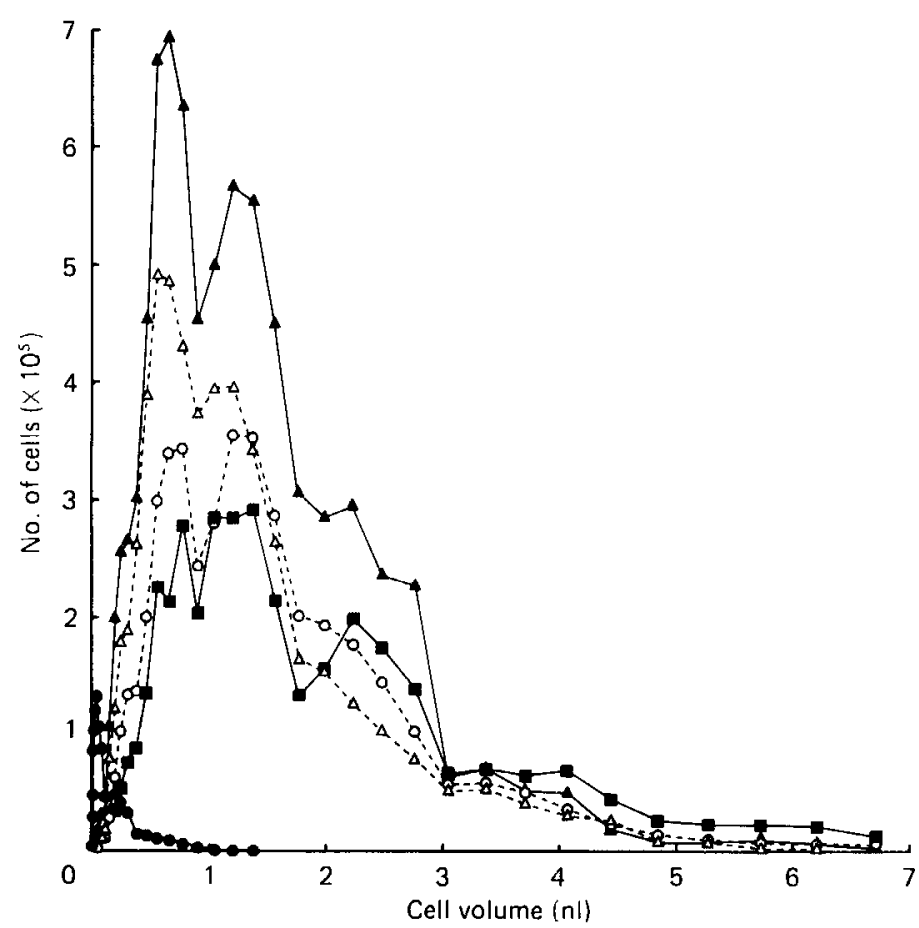

Fig. 3. Adipocyte distributions for the parametrial depot of female mice suckled in large litters of eighteen and treated with gold thioglucose, aged 13 weeks $(O), 19.5$ weeks $(\triangle), 26$ weeks $(\square), 39$ weeks (O) and 52 weeks (A). For nos of mice, see Table 1. The following distributions extended to larger cell volumes as follows: 26 weeks $19.4 \times 10^{9}$ cells up to $11.01 \mathrm{nl}, 39$ weeks $4.09 \times 10^{3}$ cells up to $7.80 \mathrm{nl}, 52$ weeks $3.48 \times 10^{3}$ cells up to $11.75 \mathrm{nl}$.

mean cell volumes generally reached a plateau and then decreased by 52 weeks in GTGtreated males. Except for the epididymal depot, significant differences in mean cell volume were seen for depots of LL and GTG-treated LL mice at 39 weeks, and also at 52 weeks in the perirenal and mesenteric depots.

The changes in adipocyte distributions with age for the parametrial depot are shown in Figs 1-3. In LL mice at 13 weeks the main population of cells peaked at a volume of $0.04 \mathrm{nl}$, while a smaller population of larger cells peaked at $0.2 \mathrm{nl}$ and tailed away up to volumes of about $1.4 \mathrm{nl}$. By 19.5 weeks, the peak of the small volume population was at $0.08 \mathrm{nl}$ but was similar in magnitude to the main population found at 13 weeks. However, there were marked increases in the number of cells present in populations peaking at $0 \cdot 15$, 0.55 and $1.2 \mathrm{nl}$. By 26 weeks of age, the number of small cells had decreased, and the number of large cells had increased, with little change in the number of cells of medium size. By 39 weeks, when there had been a significant rise in total cell number in the depot, the increase in the proportion of larger cells had continued, with the population peaking at $0.55 \mathrm{nl}$ now containing the most cells, followed by a population peaking at $0.25 \mathrm{nl}$. This latter population had increased markedly by 52 weeks and accounted for most of the increased number of cells which appeared between 39 and 52 weeks.

In SL mice, the pattern of cell-size distribution at 13 weeks in the parametrial depot was similar to that in LL mice, as was mean cell volume. Subsequently, the changes in the distributions with age followed the pattern for LL mice, except that there were more cells in the populations peaking at $1 \cdot 2$ and $2 \cdot 2 \mathrm{nl}$. However, at 52 weeks there was also an 
Table 6. Correlation coefficients and regression constants for all ages combined: $\mathrm{N}$, cell number $\left(\times 10^{6}\right)$ on depot lipid $(\mathrm{g}) ; \mathrm{V}$, cell volume $(\mathrm{nl})$ on depot lipid $(\mathrm{g})$

(Regression equation $y=a+b x$ )

\begin{tabular}{|c|c|c|c|c|c|c|c|c|c|}
\hline & & \multicolumn{4}{|c|}{ Female mice } & \multicolumn{4}{|c|}{ Male mice } \\
\hline \multicolumn{2}{|l|}{ Treatment } & $r$ & $a$ & $b$ & SE† & $r$ & $a$ & $b$ & $\mathrm{SE} \dagger$ \\
\hline & & \multicolumn{8}{|c|}{ Subcutaneous depot } \\
\hline \multirow[t]{2}{*}{ LL } & $N$ & $0.51^{* * *}$ & $1 \cdot 16$ & $0 \cdot 73$ & 0.02 & $0 \cdot 48^{* * *}$ & $1 \cdot 35$ & 0.51 & 0.02 \\
\hline & $V$ & $0 \cdot 87^{* * *}$ & 0.06 & 0.59 & $<0.01$ & $0 \cdot 76^{* * *}$ & 0.13 & $0 \cdot 43$ & $<0.01$ \\
\hline \multirow[t]{2}{*}{ SL } & $N$ & $0 \cdot 54^{* * *}$ & $1 \cdot 14$ & 0.62 & 0.02 & $0 \cdot 48^{* *}$ & $1 \cdot 27$ & $0 \cdot 71$ & 0.03 \\
\hline & $V$ & $0 \cdot 83 * * *$ & $0 \cdot 10$ & 0.49 & $<0.01$ & $0 \cdot 60^{* * *}$ & $0 \cdot 24$ & 0.35 & 0.01 \\
\hline \multirow{2}{*}{ LL GTG } & $N$ & $0.59^{* * *}$ & 0.75 & 0.55 & 0.01 & $0.62 * * *$ & $1 \cdot 03$ & 0.57 & 0.01 \\
\hline & $Y$ & $0 \cdot 66^{* * *}$ & $0 \cdot 37$ & $0 \cdot 47$ & $<0.01$ & $0 \cdot 73^{* * *}$ & $0 \cdot 20$ & 0.44 & $<0.01$ \\
\hline & & \multicolumn{8}{|c|}{ Genital depot } \\
\hline \multirow[t]{2}{*}{ LL } & $N$ & $0.56 * * *$ & $1 \cdot 64$ & 1.09 & 0.03 & $0.61 * * *$ & $1 \cdot 15$ & 0.57 & 0.01 \\
\hline & $V$ & $0.85^{* * *}$ & $0 \cdot 12$ & $0 \cdot 25$ & $<0.01$ & $0 \cdot 63^{* * *}$ & $0 \cdot 36$ & $0 \cdot 31$ & $<0.01$ \\
\hline \multirow[t]{2}{*}{ SL } & $N$ & $0.68 * * *$ & 1.99 & $0 \cdot 79$ & 0.02 & $0 \cdot 67^{* * *}$ & 0.93 & 0.68 & 0.02 \\
\hline & $V$ & $0.64 * * *$ & 0.32 & $0 \cdot 14$ & $<0.01$ & $0 \cdot 49 * *$ & 0.56 & 0.23 & 0.01 \\
\hline \multirow{2}{*}{ LL GTG } & $N$ & $0 \cdot 79^{* * *}$ & 0.75 & 0.85 & 0.01 & $0 \cdot 47 * * *$ & 1.09 & 0.40 & 0.01 \\
\hline & $V$ & $0 \cdot 56^{* * *}$ & 0.57 & $0 \cdot 10$ & $<0.01$ & $0 \cdot 65^{* * *}$ & $0 \cdot 47$ & $0 \cdot 39$ & $<0.01$ \\
\hline \multicolumn{10}{|c|}{ Perirenal depot } \\
\hline \multirow[t]{2}{*}{ LL } & $N$ & $0 \cdot 23$ & 0.69 & 0.68 & 0.05 & $0 \cdot 50^{* * *}$ & $0 \cdot 36$ & 0.96 & 0.03 \\
\hline & $V$ & $0 \cdot 80^{* * *}$ & 0.05 & $1 \cdot 12$ & 0.02 & $0.57 * * *$ & 0.35 & 0.69 & 0.02 \\
\hline \multirow[t]{2}{*}{ SL } & $N$ & $0.42 * *$ & 0.87 & $0 \cdot 56$ & 0.03 & $0.39 *$ & 0.71 & 0.29 & 0.02 \\
\hline & $V$ & $0.75 * * *$ & $0-20$ & 0.60 & 0.01 & $0 \cdot 72 * *$ & $0 \cdot 30$ & 0.83 & 0.02 \\
\hline \multirow{2}{*}{ LL GTG } & $N$ & $0.60^{* * *}$ & $0 \cdot 70$ & 0.50 & 0.01 & $0.63^{* * * *}$ & 0.47 & 0.57 & 0.01 \\
\hline & $V$ & $0 \cdot 65^{* * *}$ & 0.42 & 0.44 & $<0.01$ & $0.65^{* * *}$ & 0.37 & 0.62 & 0.01 \\
\hline \multicolumn{10}{|c|}{ Mesenteric depot } \\
\hline \multirow[t]{2}{*}{ LL } & $N$ & $0 \cdot 49^{* * *}$ & 1.83 & 1.91 & 0.06 & $0.53^{* * *}$ & $1 \cdot 40$ & 0.75 & 0.02 \\
\hline & $V$ & $0 \cdot 80^{* * *}$ & 0.02 & 0.35 & $<0.01$ & $0.79 * * *$ & $0 \cdot 12$ & 0.38 & $<0.01$ \\
\hline \multirow[t]{2}{*}{ SL } & $N$ & $0 \cdot 43^{* *}$ & $2 \cdot 05$ & $0 \cdot 31$ & $0 \cdot 15$ & $0.58 * * *$ & 1.55 & 0.63 & 0.02 \\
\hline & $V$ & $0 \cdot 77^{* * *}$ & 0.06 & 0.31 & $<0.01$ & $0.64 * * *$ & 0.23 & $0 \cdot 31$ & 0.01 \\
\hline \multirow{2}{*}{ LL GTG } & $N$ & $0.62^{* * *}$ & $1 \cdot 70$ & 0.62 & 0.01 & $0 \cdot 53^{* * *}$ & $1 \cdot 40$ & 0.51 & 0.02 \\
\hline & $V$ & $0 \cdot 78^{* * *}$ & $0 \cdot 18$ & 0.22 & $<0.01$ & $0 \cdot 76^{* * *}$ & $0 \cdot 17$ & 0.39 & $<0.01$ \\
\hline
\end{tabular}

LL, large litters; SL, small litters; LL GTG, large litters treated with gold thioglucose.

$* P<0.05, * * P<0.01, * * * P<0.001$.

$\dagger$ Standard error of slope, $b$.

increase in the number of cells in the same small volume population where an increase had occurred for LL mice at this age. Essentially similar changes in the distributions occurred in the depot from GTG-treated LL mice as in SL mice but with a further tendency to shift towards the large volume populations of cells.

The contribution of cell volume and number to the size of the depots was determined by linear regression. Within treatment at each age, significant correlations frequently occurred between cell volume and depot lipid in LL and SL mice but not in GTG-treated female LL mice (values not shown). In the depots from male mice, there were fewer such correlations. Significant correlations between cell number and depot lipid, within treatment at each age, were less frequent than for cell volume and occurred most in the depots from female GTGtreated LL mice (values not shown). When the regressions were calculated for all ages combined, clearer patterns emerged (Table 6). In female mice there were very highly significant correlations between cell volume and depot lipid for all depots within each treatment, and in male mice all correlations were significant at $P<0.01$ or better. Increased cell number was associated with increased depot lipid for all depots from the 
three treatment groups of both sexes except for the female perirenal depot. There was a tendency for the relation between cell number and depot lipid to improve according to treatment $\mathrm{LL}<\mathrm{SL}<\mathrm{LL}$ GTG, particularly in female mice.

\section{DISCUSSION}

Our longitudinal study reveals additional information about the cellular development of adipose tissue in mice resulting from different levels of preweaning nutrition and subsequent postweaning hyperphagia. In particular, it demonstrates the transient nature of the changes, not only in adipocyte volume which has been reported previously (Faust $e t$ al. 1980), but also in adipocyte number, at least in certain depots. Furthermore, it shows that the mean cell size which is attained before new cells are stimulated to appear varies from depot to depot and that there is a chronological change in cell number which appears to be independent of the size of existing adipocytes or of lipid deposition.

In our previous study of mice at 39 weeks of age, subjected to the same experimental treatment (Enser et al. 1985), male SL mice showed adipocyte hypertrophy but not hyperplasia compared with LL mice whereas in female mice both cell size and number were altered by preweaning nutrition. In the present study male SL mice had larger cells at some stages of growth in all depots and a significantly higher number of cells in the mesenteric and perirenal depots at $19 \cdot 5$ weeks and in the perirenal depot at 26 weeks (use of the term 'significant' means $P<0.05$ ). However, the effect was transient since by 39 weeks the apparent cell number in these depots from LL mice had caught up. These two depots were later-developing than the epididymal and subcutaneous depots since in LL males their contribution to total body fat increased with age much more than that of the other depots. The rate of depot development may also explain the much smaller effect of litter size on the cellularity of depots from male mice compared with female mice. The adipose tissue development in male mice at 13 weeks was much more advanced than in female mice both in terms of total body fat and in the contribution of the four depots studied to the total body lipid. If these differences extend back into the preweaning period the effects of sex on adipose tissue response might be explained by the stage of development at which the level of nutrition became critical. Presumably this would be at the later stages of suckling when milk demand was at its highest. McCance (1976) has proposed that the hypothalamic control of appetite level is set during this period. A low appetite seems to be the major cause of the effects of preweaning undernutrition on adipose tissue development since they can be reversed by increasing energy intake with high-fat diets (Faust et al. 1980; Hausberger \& Volz, 1984) or GTG-induced hyperphagia (Enser et al. 1985). The earlier development of the male mice, at a time when milk supply was less restricted, may have resulted in their appetite settings being nearly normal compared with the slower-developing females. Thus in males we observed only a transient effect of preweaning undernutrition on the volume of cells in the late-developing depots. In female mice the early developing subcutaneous depot showed a persistent lower cell volume but not number whereas the later-developing parametrial and perirenal depots showed persistent effects on cell volume and cell number. Only the female mesenteric depot did not fit this pattern, since it appeared to be the latestdeveloping depot, but had smaller cells and not fewer cells at 52 weeks.

The development of adipose tissue during normal growth is thought to occur through an initial increase in the number of visible fat cells followed by growth in cell volume (Greenwood \& Hirsch, 1974). When animals are induced to become obese later in life there is evidence to suggest that new adipocytes may be produced (Lemonnier, 1972; Faust $e t$ al. 1978; Björntorp et al. 1982; Miller et al. 1984). In depots from SL and LL female mice cell hypertrophy occurred, but only up to 39 weeks, after which there was a decrease in cell size 
which was significant in three depots. This lower cell volume was accompanied by an increase in cell number which was also significant in three depots. The increase in cell number is clearly shown in Figs 1 and 2 as an increase in cells with a smaller volume. Similar findings have been reported previously (Stiles et al. 1975; Bertrand et al. 1978) for the perirenal and epididymal fat pads of rats although their validity was questioned because isolated fat cells were measured and larger cells tend to be fragile (Gurr \& Kirtland, 1978). Although the initial increase in cell number is reported to be over by 13 weeks of age in mice (Johnson \& Hirsch, 1972) hyperplasia also occurred between 13 and 19.5 weeks in the female mesenteric depot of our LL mice, presumably because of its very late development. In the parametrial depot of these mice there was also a significant increase in cell number by 39 weeks, as well as subsequently, and these changes were similar in the depot from SL females. The cause of these increases in apparent cell number is not clear. It has been suggested that when new cells appear in later life they do so as a result of existing cells reaching a limiting size (Kral, 1976; Faust et al. 1978). Although it is possible that the size limit varies between depots, values of 1.2-1.6 $\mu \mathrm{g}$ have been quoted (Faust et al. 1978). The changes we found in the present study, particularly for the parametrial and subcutaneous depots from LL and SL mice, do not fit such a pattern. Taking the largest cell volume attained before a subsequent, but not necessarily immediate increase in cell number, we observed volumes of $0.39,1.52$ and $1.9 \mathrm{nl}$ for the parametrial depot from LL, SL and GTGtreated LL mice respectively. On the basis of cell volume there was no apparent need for the cell number to increase in this depot of LL females since a fourfold increase in cell volume to the size already existing in SL and GTG-treated LL mice of the same age would have accommodated the fourfold increase in depot lipid. The parametrial depot in LL mice did not grow between 39 and 52 weeks and, as its cells were half the size of those in the depot from SL and LL GTG mice, there was seemingly no need for the $65 \%$ increase in cell number which occurred. The depot in SL mice at 26 weeks contained the same number of cells as that in LL mice at 39 weeks and the depot was twice as large. In SL mice an increase in the number of cells in the parametrial depot occurred between 26 and 39 weeks, apparently initiated by the large mean size, $1.52 \mathrm{nl}$, of the cells at 26 weeks, and an increase of one-third in the weight of the depot lipid. However, this increase of $78 \%$ in cell number was followed by an $82 \%$ increase between 39 and 52 weeks despite the fact that the depot size increase was only $30 \%$ and the same number of cells present at 39 weeks was in GTGtreated LL mice already sustaining a depot of similar size. It is possible, however, that the hyperplasia after 39 weeks in SL mice was merely the revelation through lipid accumulation of cells produced in the earlier hyperplasia. Figs 1-3 suggest possible explanations for these changes. Up to 26 weeks the parametrial depot from all three treatment groups grows through an increase in the size of an existing population of cells with a change in cell distribution towards larger volumes and this continues up to 39 weeks in LL mice. Differences in overall volume and number appear to have little effect on the pattern of growth suggesting that the volume distributions which occur are dependent on some feature of the tissue, possibly the structure of the capillary bed and the site of cells within it. Between 39 and 52 weeks there was a clear development of more cells in the smallvolume categories previously observed at 13 and 19 weeks with relatively more of these cells in the larger fractions of the depot of GTG-treated LL mice, which was the biggest. Although our findings cannot prove that these newly recognizable cells had only just been synthesized, this is the simplest explanation. It is hard to see, otherwise, how such cells should have been maintained in a precursor state during the very rapid growth of adipose tissue after GTG treatment. The nature of the changes in cell-volume distribution with age also explains why it is difficult to obtain useful information on the relative contribution of cell volume and number to depot size using regression analysis. In general, larger depots 
have larger cells, although rapid hyperplasia can decrease the mean cell volume. If cell volume reaches a maximum, then the size of depots will be related closely to cell number but as we have seen in the present study cell numbers appear to change for other reasons and some cells may be capable of further growth at the time 'new' cells appear (Hausman, 1985).

We conclude that the effects of preweaning undernutrition on adipose tissue development in mice are fully reversible with time or adequate nutrition, or both. We suppose that they stem from changes in the appetite settings although we would need to measure food intake to confirm this. We propose that the tissues of male mice are less affected than those of females because the development of their hypothalamus may be more advanced when the stress of preweaning undernutrition becomes acute and hence their subsequent voluntary food intake is nearer to normal. The susceptibility of different fat depots to the effects of litter size appears to depend on rate of development with early maturing depots being altered less or recovering first since the relation between fat distribution and total body lipid is hardly changed by litter size. The stimulus for adipocyte hyperplasia remains obscure. We can find only limited evidence to support the critical size hypothesis while there is clear evidence to support a chronological change. Another possibility is that preweaning undernutrition not only resets the appetite level but also the critical size. Although the mechanism for such an effect can only be speculated on, the results confirm our earlier finding that GTG-induced damage to the hypothalamus prevents hyperplasia in epididymal adipose tissue.

The authors wish to thank Mrs J. M. Almond, Mr D. J. Restall and Mr G. Fitton for their help with this study.

\section{REFERENCES}

Aubert, R., Suquet, J. P. \& Lemonnier, D. (1971). Compte Rendu de l'Académie des Sciences, Paris, Série D 273, 2636-3638.

Bertrand, H. A., Masoro, E. J. \& Yu, B. P. (1978). Science 201, 1234-1235.

Björntorp, P., Karlsson, M. \& Pettersson, P. (1982). Metabolism, Clinical and Experimental 31, 366-373.

Eisen, E. J. \& Leatherwood, J. M. (1978). Journal of Nutrition 108, 1652-1662.

Enser, M., Roberts, J. \& Whittington, F. M. (1985). British Journal of Nutrition 54, 645-654.

Faust, I. M., Johnson, P. R. \& Hirsch, J. (1980). Journal of Nutrition 110, 2027-2034.

Faust, I. M., Johnson, P. R., Stern, J. S. \& Hirsch, J. (1978). American Journal of Physiology 235, E279-E286.

Greenwood, M. R. C. \& Hirsch, J. (1974). Journal of Lipid Research 15, 474-483.

Gurr, M. I. \& Kirtland, J. (1978). International Journal of Obesity 2, 401-425.

Hausberger, F. X. \& Volz, J. E. (1984). Physiology and Behaviour 33, 81-87.

Hausman, G. J. (1985). In New Perspectives in Adipose Tissue: Structure and Function, pp. 1-21 [A. Cryer and R. L. R. Van, editors]. London: Butterworths.

Johnson, P. R. \& Hirsch, I. (1972). Journal of Lipid Research 13, 2-11.

Knittle, J. L. \& Hirsch, J. (1968). Journal of Clinical Investigation 47, 2091-2098.

Kral, J. G. (1976). American Journal of Physiology 231, 1090-1096.

Lemonnier, D. (1972). Journal of Clinical Investigation 51, 2907-2915.

McCance, R. A. (1976). Proceedings of the Nutrition Society 35, 309-313.

Martin, R. J. (1974). Growth 38, 465-476.

Miller, W. H., Faust, I. M. \& Hirsch, J. (1984). Journal of Lipid Research 25, 336-347.

Reyne, Y., Teyssier, J., Nouguès, J. \& Tébibal, S. (1985). Journal of Lipid Research 26, 1036-1046.

Robelin, J. (1981). Journal of Lipid Research 22, 452-457.

Sjöström, L., Björntorp, P. \& Vrana, J. (1971). Journal of Lipid Research 12, 521-530.

Stiles, J. W., Francendese, A. \& Masoro, E. J. (1975). American Journal of Physiology 229, 1561-1568.

Wise, A. (1975). Nutrition and Metabolism 19, 291-298. 